\title{
Agenesis of Isthmus of Thyroid Gland in the Presence of Ectopic Thyroid Tissue Associated with Papillary Carcinoma
}

\author{
Kesici Ugur1, Kesici Sevgi2, Kesicioglu Tugrul3 and Demet Sengul4
}

\begin{abstract}
The thyroid is an endocrine gland composed of two lateral lobes connected by a strip of thyroid tissue called an isthmus. The thyroid gland is usually associated with extensive morphological variations and developmental anomalies. During the 4th intrauterine week, the thyroid gland begins to develop mainly from the invagination of the endodermal cells of the ventral floor of the primitive pharynx. One of the anomalies of the thyroid gland is the agenesis of the isthmus of the thyroid. It is a rare condition and very few cases have been reported in the literature. Another rare developmental abnormality is the presence of ectopic thyroid tissues, which are characterised by the presence of thyroid tissue in locations other than the anterolateral region of the second and fourth tracheal cartilages. Ectopic thyroid tissues are most commonly found in the lingual region but are also found in the other head/neck localisations as well. In this present case report, a 54-year-old female patient with the agenesis of the isthmus of the thyroid gland with accompanying tissues of multifocal and multicentric papillary thyroid carcinoma will be discussed. When an agenesis of the isthmus of the thyroid is detected, the agenesis of the thyroid lobes or the presence of an ectopic thyroid tissue must be considered. Especially in the patients who will undergo a thyroid surgery, it should not be forgotten that the identification of an agenesis of the isthmus as well as the other thyroid anomalies during the preoperative examination, will make a remarkable contribution in deciding the strategy of the surgery and will help in preventing the development of surgical complications. However, it is not always possible to detect the presence of these anomalies, during the preoperative examinations of the patients who will undergo thyroid surgeries; therefore, one must be careful with regard to these type of anomalies in the perioperative examinations. To the best of authors' information, the present case is considered to be the first in the literature in English, presenting with an agenesis of the isthmus of the thyroid gland in the presence of ectopic thyroid tissues associated with papillary carcinoma.
\end{abstract}

Key Words: Thyroid agenesis, Thyroid isthmus, Thyroid gland, Ectopic thyroid, Carcinoma, Papillary.

\section{INTRODUCTION}

The thyroid is an endocrine gland composed of two lateral lobes connected by a thyroid tissue called the isthmus. During the 4th intrauterine week, the thyroid gland begins to develop mainly from the invagination of the endodermal cells of the ventral floor of the primitive pharynx. 1 The thyroid gland often presents with extensive morphological variations and developmental anomalies. ${ }^{2-4}$ One of these anomalies is the agenesis of the isthmus of the thyroid gland. It is a rare condition and there are very few cases reported in the literature. 2,3 In line with our reviews, the first case detected with an agenesis of the isthmus of the thyroid gland, associated with papillary carcinoma, was reported by Vayisoglu et al. ${ }^{5}$ in 2013 in the literature in English. On the other

1 Department of General Surgery, Faculty of Medicine, University of Beykent, Istanbul, Turkey

2 Department of Anesthesiology, Istanbul Aydin University, Vocational School of Health Services, Istanbul, Turkey

3 Department of General Surgery / Pathology4, University of Giresun, School of Medicine, Giresun, Turkey

Correspondence: Dr. Kesici Ugur, Department of General Surgery, Faculty of Medicine, University of Beykent, Istanbul, Turkey

E-mail:ugurkesici77@mynet.com

Received: December 22, 2017; Accepted: September 10, 2018 hand, the present case is considered to be the first case in which an agenesis of the isthmus of the thyroid gland was identified along with the presence of ectopic thyroid tissue, associated with papillary carcinoma, in the literature in English.

\section{CASE REPORT}

In this case report, a 54-year-old female patient with an agenesis of the isthmus of the thyroid gland in the presence of multifocal and multicentric papillary thyroid carcinoma was discussed. In the physical examination of the patient, there were palpable nodules in both lobes of the thyroid. The medical and family histories of the patient were non-specific. In the preoperative period, the neck ultrasonography (USG) revealed nodules of $12.5 \times 10.5 \mathrm{~mm}$ and $12.1 \times 8.4 \mathrm{~mm}$ in size in the left lobe of the thyroid gland, displaying widespread microcalcifications along with the nodules with micro-macro calcifications adjacent to the left carotid artery. In addition, a calcified nodule of $3 \mathrm{~cm}$ in size was identified in the superior mediastinum on the left. The results of the thyroid function tests and other laboratory tests were normal in the preoperative period. The USG-guided fine needle aspiration cytology performed preoperatively on the ectopic thyroid tissue at the retrosternal region was reported to be in favour of a lesion with malignant nature. A total thyroidectomy was scheduled for the patient. 


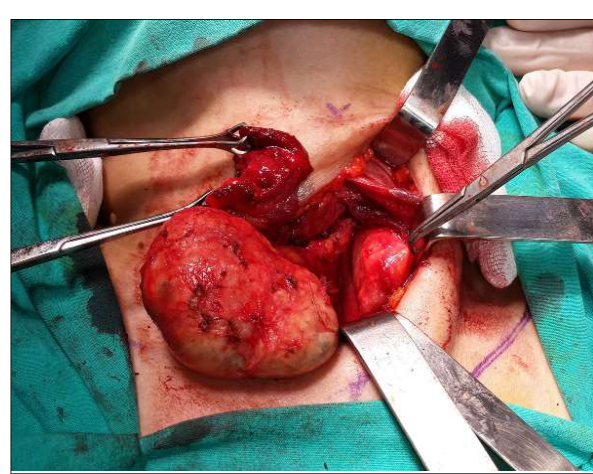

Figure 1: Left retrosternal ectopic thyroid tissue.

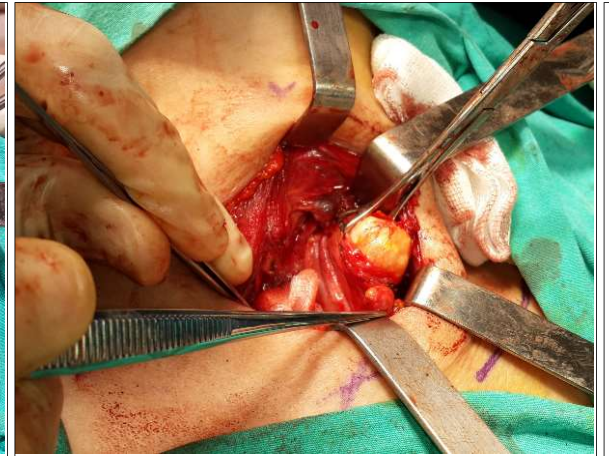

Figure 2: Left lateral ectopic thyroid tissue.

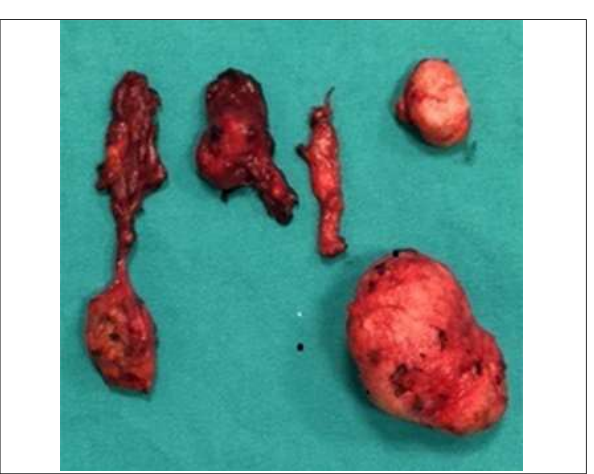

Figure 3: Postoperative surgical tissue.
The agenesis of the isthmus of the thyroid gland was identified during the surgical exploration. In addition, during the surgery, calcified ectopic thyroid tissues were observed, an approximately $6 \times 4 \mathrm{~cm}$ one in the left retrosternal region and an approximately $2 \times 1.5 \mathrm{~cm}$ one on the left, laterally, adhering to the jugular vein and the nervus vagus. The retrosternal ectopic thyroid tissue on the left is shown in Figure 1; and the ectopic thyroid tissue located laterally on the left is shown in Figure 2.

After the total excision of both ectopic thyroid tissues on the left and of both thyroid lobes, the dissection of the left central lymph node was performed. The image of the excised tissues during the surgery is shown in Figure 3.

The histopathological examination revealed a multicentric papillary thyroid carcinoma including a $3 \mathrm{~cm}$ and a $1 \mathrm{~cm}$ foci in the right thyroid lobe, a $2.5 \mathrm{~cm}$ one in the left thyroid lobe and a $6.5 \mathrm{~cm}$ one in the left retrosternal ectopic thyroid tissue. In addition, four metastatic foci of papillary carcinoma were detected in the excised lymph node. No remaining tissues were identified in the thyroid scintigraphy performed on the postoperative $12^{\text {th }}$ day.

\section{DISCUSSION}

An ectopic thyroid tissue remains to be a rare developmental abnormality that is characterised by the presence of thyroid tissue in locations other than the anterolateral region of the second and fourth tracheal cartilages. Ectopic thyroid tissues are most commonly found in the lingual region but they are found in the other head/neck localisations as well. Its specific prevalence approximately ranges from $1 / 100.000$ to $1 / 300.000$ persons and it is identified in 1/4.000-1/8.000 patients with a thyroid disease. The etiology of this condition is not known precisely. The ectopic tissue is also susceptible to undergo various pathological changes that may occur in a thyroid gland, which is located in the natural anatomical location. Asymptomatic patients with ectopic thyroid tissues do not usually require treatment. However, these patients should be monitored. For those patients developing symptoms, the modes of the treatment depend on the size of the gland, the nature of the symptoms, the status of the thyroid function, and on the histological findings. A surgical excision is often required to treat this condition. 6 In the present case report, the thyroid function tests were normal preoperatively. However, the preoperative USG-guided fine needle aspiration cytology of the ectopic thyroid tissue in the retrosternal region reported findings favouring lesions in malignant nature. Therefore, a total thyroidectomy was performed. The agenesis of the isthmus of the thyroid gland was identified during the surgical exploration.

Although the agenesis of the thyroid isthmus is reported to be associated with genetic factors, developmental anomalies, and especially with TITF 1-2 genes and chromosome 22 mutations, the etiology is not known precisely.7-9 In the literature, the incidence of the agenesis of the thyroid isthmus is reported to be $0.5-10 \% .5$ However, the exact percentages are not known due to the limited number of case reports in the literature and the incidence data has been derived from cadaver series. ${ }^{7}$

Clinically, the agenesis of the thyroid isthmus can be identified in the scintigraphic examination, if the thyroid stimulating hormone (TSH) levels are high. Besides, the diagnosis can be made in radiological examinations with USG, computerised tomography (CT), and magnetic resonance imaging (MRI). In some cases, it may be revealed during a surgical procedure. 3,4 The agenesis of the thyroid isthmus and the existence of ectopic thyroid tissues in the patient in the present case report was detected perioperatively. The reason of this condition has been associated with the fact that the ectopic thyroid tissue extending to the left retrosternal region was so large that it extended to the medial regions of the left thyroid lobe and expanded the left thyroid lobe medially.

In the differential diagnosis of the agenesis of the thyroid isthmus, diseases such as thyroiditis, an autoimmune thyroid nodule, a primary thyroid carcinoma, metastases, and amyloidosis must be considered; and it must be kept in mind that an agenesis of the thyroid isthmus may exist together with a thyroid lobe agenesis or with 
ectopic thyroid tissues or with parathyroid hyperplasia.4,5,10 This is especially quite important in the determination of the surgical strategy preoperatively and in preventing possible surgical complications. But it should not be forgotten that the presence of an agenesis of the thyroid isthmus or ectopic thyroid tissues may not always be identified preoperatively as reported in the present case report, and in some previously reported cases in the literature. ${ }^{3}$ Therefore, the patients who undergo a thyroid surgery, anomalies of this type must be kept in mind during the perioperative period.

In conclusion, when an agenesis of the thyroid isthmus agenesis is identified, it must be known that this condition may co-exist with the agenesis of the thyroid lobes or with ectopic thyroid tissues. In the differential diagnosis, several diseases should be considered including thyroiditis, an autoimmune thyroid nodule, primary thyroid carcinoma, metastases, and amyloidosis. Especially in patients for whom a thyroid surgery is scheduled, it must not be forgotten that identification of an agenesis of the thyroid isthmus or of other thyroid anomalies will make significant contributions to the decision-making process in determining the surgical strategies and will allow prevention of possible surgical complications. However, one must be quite observant of these anomalies perioperatively in all the patients who shall undergo a thyroid surgery because the existence of these anomalies cannot always be identified during the preoperative examinations.

\section{REFERENCES}

1. Yaman H, Durmaz A, Arslan HH, Ozcan A, Karahatay S, Gerek M. Thyroglossal duct cysts: evaluation and treatment of 49 cases. B-ENT 2011; 7:267-71.

2. Kumar GP, Satyanarayana N, Vishwakarma N, Guha R, Dutta AK, Sunitha P. Agenesis of isthmus of thyroid gland, its embryological basis and clinical significance - a case report. Nepal Med Coll J 2010; 12:272-4.

3. Kesici $\mathrm{U}$, Kesici $\mathrm{S}$. Agenesis of the isthmus of the thyroid gland. Turk J Surg 2018; 34:60-1.

4. Dixit D, Shilpa MB, Harsh MP, Ravishankar MV. Agenesis of isthmus of thyroid gland in adult human cadavers: A case series. Cases J 2009; 2:6640.

5. Vayisoglu Y, Ozcan C, Gen R, Eti CM, Sut H, Gorur K. Thyroid isthmus agenesis associated with thyroid papillary carcinoroid isthmus agenesis associated with thyroid papillary carcinoma. J Craniofac Surg 2013; 24:428-9.

6. Guerra G, Cinelli M, Mesolella M, Tafuri D, Rocca A, Amato B, et al. Morphological, diagnostic and surgical features of ectopic thyroid gland: a review of literature. Int J Surg 2014; 12:3-11.

7. Ozkan OF, Asik M, Toman H, Ozkul F, Cikman O, Karaayvaz M. Agenesis of isthmus of the thyroid gland in a patient with graves-basedow disease and a solitary nodule. Case Rep Surg 2013; 608481.

8. Sankar KD, Bhanu PS, Bapuji P. Agenesis of isthmus of thyroid gland with embryological and clinical basis. Narayana Med $\mathrm{J}$ 2012; 1:32-4.

9. Gangbo E, Lacombe D, Alberti EM, Taine L, Saura R, Carles DN. Trisomy 22 with thyroid isthmus agenesis and absent gall bladder. Genet Couns 2004; 15:311-5.

10. Pastor VJF, Gil VJA, De Paz Fernández FJ, Cachorro MB. Agenesis of the thyroid isthmus. Eur J Anat 2006; 10:83-4. 